\title{
Ectopic third molar in the mandibular sigmoid notch: Report of a case and literature review
}

\author{
Yavuz Fındık ${ }^{1}$, Timuçin Baykul ${ }^{2}$ \\ ${ }^{1} \mathrm{DDS}, \mathrm{PhD}$, Assistant Professor, Department of Oral and Maxillofacial Surgery, Faculty of Dentistry, Süleyman Demirel University, \\ Isparta, Turkey \\ ${ }^{2} \mathrm{DDS}, \mathrm{PhD}$, Professor, Department of Oral and Maxillofacial Surgery, Faculty of Dentistry, Süleyman Demirel University, Isparta, \\ Turkey
}

Correspondence:

Süleyman Demirel University

Faculty of Dentistry

Department of Oral and Maxillofacial Surgery

Isparta, Turkey

yavuzfindik32@hotmail.com

Findık Y, Baykul T. Ectopic third molar in the mandibular sigmoid notch: Report of a case and literature review. J Clin Exp Dent. 2015;7(1):e133-7. http://www.medicinaoral.com/odo/volumenes/v7i1/jcedv7ilp133.pdf

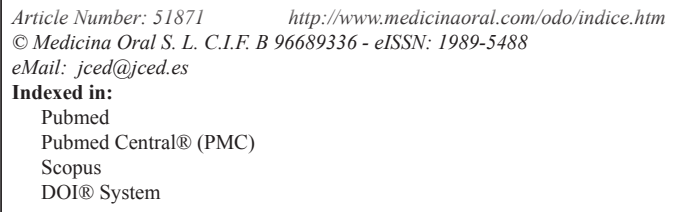

\begin{abstract}
Purpose: To evaluate the etiopathogenesis, clinical features and surgical approaches for removal of ectopic third molars in the mandible.

Methods: We report a case of an impacted mandibular third molar dislocated on mandibular sigmoid notch. 20 cases of ectopic mandibular third molars reported in the English-language literature, identified from Pubmed and Medline databases are also reviewed.

Results: Among the 20 article reported in the presented study, ectopic third molars were generally located in the condylar region. The common symptoms of the clinical examination were pain, trismus, swelling, temporomandibular joint syndroms or no symptoms.

Conclusions: Ectopic third molar may be asymptomatic initially with clinical manifestations, later on as adjacent structures are affected. The surgical approach must be carefully planned for the aim of choosing the more conservative technique that produces the minimum trauma to patients.
\end{abstract}

Key words: Ectopic third molar, sigmoid notch, cyst.

\section{Introduction}

Ectopic teeth often impact in unusual positions or at a distance from their normal anatomic location. Ectopic eruption of a tooth into dental structures is a common entity, while ectopic eruption of a tooth in other sites is infrequent (1). Reported sites include the maxillary sinus, palate, mandibular condyle, coronoid process, orbit, nasal cavity or through the skin $(2,3)$. Ectopic teeth may be supernumerary, deciduous, or permanent.

Permanent mandibular third-molar impaction is a com- mon condition in populations, with a frequency of $20 \%$ to $30 \%$. Ectopic mandibular third molars, however, are unusual, with their heterotopic positions reported in the condylar area, in the ascending ramus of the mandible, or in the coronoid process. Most cases of ectopic third molars are asymptomatic and are usually found during routine clinical and radiographic investigations. In the present study, we report a case of an ectopic third molar on the right sigmoid notch with multiple cysts and compare it with the literature reports of this anomaly. 


\section{Material and Methods}

We performed a literature search using the PubMed database. We used ectopic third molar and mandible as key words. Of the 45 articles found, we only considered the English literature and well-documented cases of ectopic third molars in the mandible. Our inclusion criteria were as follows: English-language articles generated by the Pubmed database search containing at least one case of an ectopic third molar in the mandible; and articles containing cases of patients with ectopic third molars located in the mandibular condyle, coronoid, and sigmoid regions (Table 1). We compared the results of our search with the following case study. no signs of any significant pathology in relation to any tooth or tissue. Panoramic radiograph examination revealed a radiolucent area surrounding the crown of the fully formed, ectopic mandibular third molar in right mandibular sigmoid notch region (Fig. 1). Cystic lesions were also seen in the left maxillary and right mandibular area. Cone beam CT scans showed the impacted tooth with the proximity to the lingual cortical bone and there was also cortical bone exposure in the coronal images (Fig. 2).

The surgical staff carried out the surgical procedure with the patient under general anesthesia. They obtained intraoral access via an incision on the anterior edge of the

Table 1. Ectopic third molars in the literature.

\begin{tabular}{|c|c|c|c|c|}
\hline Authors & Age & Gender & Position of the tooth & Surgical choice \\
\hline Traiger J. et al. ${ }^{4} 1965$ & - & - & Sigmoid notch & - \\
\hline Szerlip et al..$^{5} 1978$ & 50 & Female & subcondylar & Intraoral \\
\hline Burton y Scheffer. ${ }^{6} 1980$ & 57 & Female & Bilateral mandibular ramus & 1ntraoral and extraoral \\
\hline Srivastava y Singh. ${ }^{7} 1982$ & 40 & Female & Condylar area & No treatment \\
\hline Granite EL et al. ${ }^{8} 1985$ & - & - & Subcondylar-sigmoid notch & Asymptomatic \\
\hline Mehta DS et al. ${ }^{9} 1986$ & - & - & Sigmoid notch & - \\
\hline Chongruk et al. ${ }^{10} 1991$ & 27 & Female & Coronoid region & No treatment \\
\hline Toranzo et al. ${ }^{11} 1992$ & 70 & Female & Coronoid region & Intraoral \\
\hline Bux et al. ${ }^{12} 1994$ & 66 & Female & Subcondylar & Extraoral \\
\hline Keros et al. ${ }^{13} 1997$ & 41 & Male & Coronoid region & - \\
\hline Medici et al. ${ }^{14} 2001$ & 41 & Female & Condylar & Intraoral \\
\hline Tumer et al. ${ }^{15} 2002$ & 47 & Male & Subcondylar & Extraoral \\
\hline Wassouf et al. ${ }^{16} 2003$ & 49 & Female & Condylar & Intraoral \\
\hline Suarez-Cunqueiro et al. ${ }^{17} 2003$ & 45 & Male & Condylar & Intraoral \\
\hline Salmeron et al..$^{18} 2007$ & 42,53 & Female, male & Condylar, subcondylar & Extraoral \\
\hline Wang et al. ${ }^{19} 2008$ & 31 & Female & Condylar & Intraoral \\
\hline Gadre et Waknis. ${ }^{20} 2010$ & 30 & Female & Condylar & Intraoral \\
\hline Bortoluzzi et Manfro. ${ }^{21} 2010$ & 68 & Female & Condylar & Intraoral \\
\hline Pace et al. ${ }^{22} 2010$ & 53 & Male & Subcondylar & Extraoral \\
\hline Procacci et al. ${ }^{23} 2011$ & 42 & Female & Coronoid & Intraoral \\
\hline Shivashankara et al. ${ }^{24} 2012$ & 45 & Male & Subcondylar & Extraoral \\
\hline Iglesias-Martin et al. ${ }^{25} 2012$ & 53 & Female & Subcondylar & Extraoral \\
\hline Lambade et al. ${ }^{26} 2013$ & 35 & Female & Condylar & Extraoral \\
\hline Presented case 2013 & 45 & Male & Sigmoid notch & Intraoral \\
\hline
\end{tabular}

A 45-year-old man was referred to the Department of Oral and Maxillofacial Surgery, Faculty of Dentistry Hospital (Isparta, Turkey), in August 2011 for the evaluation and assessment of an impacted lower right third molar in the mandibular sigmoid notch associated with a radiolucent lesion and multiple cysts located in the jaws. His medical history also did not give any significant information that could associated with the presenting symptoms. On intra oral examination, there were mandibular ramus and along the external oblique ridge. They performed the periosteal dissection was done lingually to expose the sigmoid notch of the mandible. They used a round burr was used to make cuts on the cortical bone of the mandible where they had estimated the crown of the ectopic tooth from the CT scans and the panoramic radiograph.

They elevated the tooth was then elevated out of the bony socket by an elevator via the bony window. Then they 


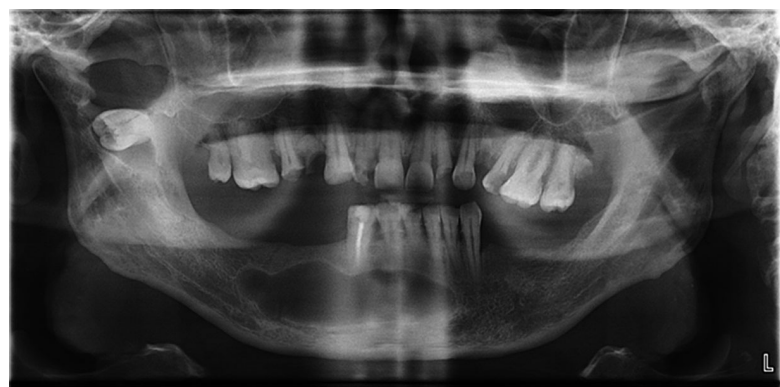

Fig. 1. Panaromic view of the patient before the surgery.

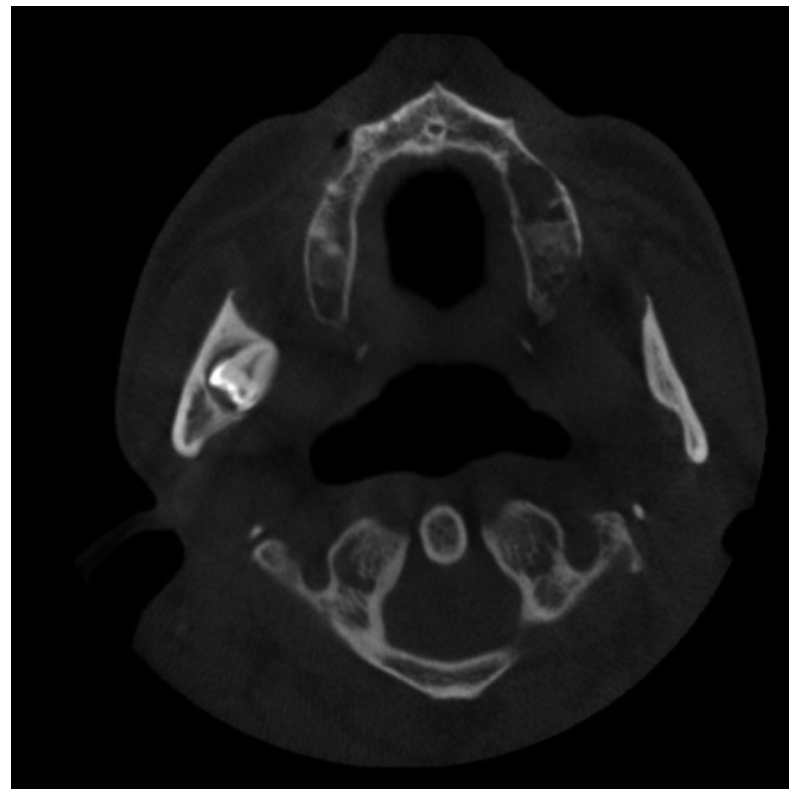

Fig. 2. CBCT view of the ectopic third molar.

enucleated the other cystic lesions located in the maxilla and mandible, were enucleated without any complications. They sent the enucleated soft tissues were sent to pathology and sutured the wound after irrigation. The pathology report revealed tissue compatible with a dentigerous cyst around the ectopic tooth; radicular cysts in the maxilla; residual csyt in the mandible.

The postoperative phase was uneventful (Fig. 3). The patient was under antibiotic coverage along with antiinflammatory analgesics for 7 days. The patient was under regular follow-up care for 18 months. There was no deviation of the mandible and preoperative occlusion was maintained without any functional discrepancy.

\section{Results}

Among the 23 articles reported in the presented study, ectopic third molars were generally located in the condylar region. The common symptoms of the clinical examination were pain, trismus, swelling, temporomandibular joint syndrome or no symptoms (5-25). Fever with acute inflammation and drainage of purulent material through intraoral or extraoral areas have also occured

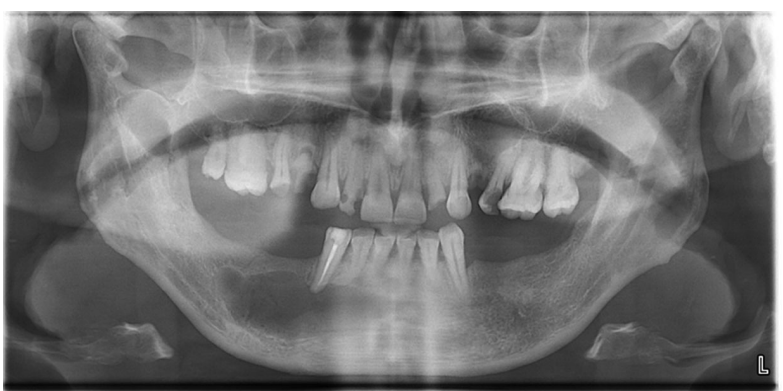

Fig. 3. Panaromic view of the patient after the removal of the ectopic third molar and other cysts.

$(7,12)$. Among the 23 case reports summarized in the table, 7 were in men , 13 cases were in women and 3 were unknown.

Sixteen cases received extraction of the ectopic third molar. Ten of the ectopic third molars were extracted through intraoral access, and the other 6 were extracted through extraoral access. In the extraoral approaches, the most frequently used access routes were the submandibular and retromandibular, because they provide a good surgical exposure especially to the body and ascending ramus, and with a higher difficulty, to the condylar region. In one study, the authors presented an endoscopically assisted surgical technique for the removal of an ectopic lower third molar in the condylar process (17). Generally, all studies described a radiolucent image around the ectopic molar upon radiography, with the diagnosis of a dentigerous cyst. The associated cyst was infected in some cases $(6,11)$. The infected cyst in the coronoid process described by Toranzo et al. is the only case in which the adjacent cyst apparently did not encompass the crown of the ectopic third molar. In one case report, authors presented a case where an ectopically placed mandibular third molar led to an extraoral sinus and scar formation below the ear lobule with osteomyelitis of the mandibular condyle (26).

\section{Discussion}

Ectopic teeth are located in the jawbones or regions other than the alveolar arch. Ectopic eruption of a tooth is rare; however, there have been few reports of tooth in the nose, mandibular condylary and coronoid processes and maxillary sinus $(25,27,28)$. Most of the cases in the mandibular coronoid and condylary regions had symptomatic signs; common symptoms of the clinical examination were pain, trismus, swelling, and temporomandibular joint problems. On the other hand, ectopic teeths are often discovered in routine clinical or radiographic examinations; as some of the cases were asymptomatic, like the case study above.

The aetiology of ectopic eruption is still unclear, and reaches have suggested many theories, including trauma, infection, pathologic conditions, crowding and develop- 
mental anomalies. Odontogenesis is a complex process, and abnormal tissue interactions between the oral epithelium and the underlying mesenchymal tissue during development may potentially result in ectopic tooth development and eruption (29). A mandibular third molar may be displaced by a lesion such as a cyst or a tumor (14). The displacement of tooth buds by the expansion of progressively growing dentigerous cysts may result in the displacement of the tooth to other areas.

In some of the reports in the literature review, the cysts associated with the ectopic third molars were very small like our case. Such cysts may have once occupied the entire ramus, but their walls may have been perforated, which resulted in drainage and decompression $(12,14)$. This pathological process may support the idea that a dentigerous cyst was the etiologic factor of ectopic eruption in the subject of our case study.

Most dentigerous cysts are solitary. Bilateral and multiple cysts are usually found in association with a number of syndromes that include cleidocranial dysplasia. In the absence of these syndromes, multiple cysts are rare.30 This is a report of the unusual occurrence of nonsyndromic adjacent cysts. A literature search has shown no report of a similar case.

Treatment of ectopic third molars in the coronoid and condylar regions is recommended to avoid the morbidity caused by infection of the cyst, malfunction of the temporomandibular joint, and risk of fracture in an area with a very thin bone. In cases of symptom-free highly aberrant wisdom teeth or without urgent necessity, annual follow-up visits to monitor the growth of the lesion are appropriate.

In the cases described in the literature, surgeons have used several surgical approaches have been used, such as extraoral (preauricular, retromandibular, endoaural), intraoral, and recently, endoscopic approaches. The most commonly used extraoral approaches were submandibular access and preauricular approach. These external approaches have the advantage of good exposure of the surgical site but may result in complications such as extraoral scar formation, damage of joint components, facial nerve injury in the case of preauricular access, or damage of the marginal branch of the seventh cranial nerve in the case of submandibular access (14).

Surgeons have use endoscopy because it magnifies the surgical field. Especially in intraoral approaches, this is an important property. However, the cost of endoscopes and the lack of training facilities prohibit the routine use of endoscopy.

The selection of the surgical approach is basically linked to the experience and preference of surgeons. In one study, surgeons presented an endoscopically assisted surgical technique for the removal of an ectopic lower third molar in the condylar process associated with a dentigerous cyst (17). In a case report, surgeons used an endoau- ral approach that causes low morbidity from facial palsy and gives adequate exposure of the temporomandibular region (16). In the presented case, we used an intraoral approach to avoid visible scars and facial nerve injury. in some cases, authors used miniplates, especially impacted third molars in the condyle, to avoid fractures (22) because they thought the loss of some bony support at the condylar neck post-surgery would increase the risk of a pathological fracture in such cases.

In our literature review, the authors agreed that the treatment should be carefully planned according to the location and position of the ectopic tooth and morbidity associated with surgery, with the aim of choosing the most conservative technique that produces the least possible trauma to the patient.

In conclusion, occurrence of an ectopic tooth in the coronoid or condylar regions and association of a dentigerous cyst with it is a rare phenomenon. Its presence may be the asymptomatic initially with later clinical manifestations as adjacent structures are affected. The surgical approach must be carefully planned for the aim of choosing the most conservative technique that produces the minimum trauma to patients. Postoperative followup with radiographic examination at regular intervals is mandatory to rule out any recurrence.

\section{References}

1. Elonga S, Palaniappan SP. Ectopic tooth in the roof of the maxillary sinus. Ear Nose Throat J. 1991;70:365-6.

2. Yeung KH, Lee KH. Intranasal tooth in a patient with a cleft lip and alveolus. Cleft Palate Craniofac J. 1996;33:157-9.

3. Smith RA, Gordon NC, DeLuchi SF. Intranasal teeth. Oral Surg Oral Med Oral Pathol. 1979;47:120-2.

4. Traiger J, Koral K, Catania Aj, Nathan As. Impacted Third Molar And Dentigerous Cyst Of The Sigmoid Notch Of The Mandible. Report Of A Case. Oral Surg Oral Med Oral Pathol. 1965;19:459-61.

5. Szerlip L. Displaced third molar with dentigerous cyst an unusual case. J Oral Surg. 1978;36:551-2.

6. Burton DJ, Scheffer RB. Serratia infection in a patient with bilateral subcondylar impacted third molars and associated dentigerous cysts: report of case. J Oral Surg. 1980;38:135-8.

7. Srivastava RP, Singh G. An unusual impacted inverted molar in mandibular condyle with preauricular sinus (a case report). J Indian Dent Assoc. 1982;54:67-9.

8. Granite EL, Isaacs M, Kross JF. Asymptomatic impacted mandibular third molar in the subcondylar-sigmoid notch region associated with extensive sclerotic bone. J Oral Med. 1985 Apr-Jun;40:91-2, 97.

9. Mehta DS, Mehta MJ, Murugesh SB. Impacted mandibular third molar in the sigmoid notch region associated with dentigerous cyst-a case report. J Indian Dent Assoc. 1986;58:545-7.

10. Chongruk C. Asymptomatic ectopic impacted mandibular third molar. Oral Surg Oral Med Oral Pathol Oral Radiol Endod. 1991;71:520.

11. Toranzo Fernandez M, Terrones Meraz MA. Infected cyst in the coronoid process. Oral Surg Oral Med Oral Pathol Oral Radiol Endod. 1992;73:768.

12. Bux P, Lisco V. Ectopic third molar associated with a dentigerous cyst in the subcondylar region: report of case. J Oral Maxillofac Surg. 1994;52:630-2.

13. Keros J, Susic M. Heterotopia of the mandibular third molar: a case report. Quintessence Int. 1997;28:753-4.

14. Medici A, Raho MT, Anghinoni M. Ectopic third molar in the condylar process: case report. Acta Biomed Ateneo Parmense. 2001;72:115-8. 
15. Tumer C, Eset AE, Atabek A. Ectopic impacted mandibular third molar in the subcondylar region associated with a dentigerous cyst: a case report. Quintessence Int. 2002;33:231-3.

16. Wassouf A, Eyrich G, Lebeda R, Gratz KW. Surgical removal of a dislocated lower third molar from the condyle region: case report. Schweiz Monatsschr Zahnmed 2003;113:416-20.

17. Suarez-Cunqueiro MM, Schoen R, Schramm A, Gellrich NC, Schmelzeisen R. Endoscopic approach to removal of an ectopic mandibular third molar. Br J Oral Maxillofac Surg. 2003;41:340-2.

18. Salmeron JI, del Amo A, Plasencia J, Pujol R, Vila CN. Ectopic third molar in condylar region. Int J Oral Maxillofac Surg. 2008;37:398-400.

19. Wang CC, Kok SH, Hou LT, Yang PJ, Lee JJ, Cheng SJ, Kuo RC, Chang HH. Ectopic mandibular third molar in the ramus region: report of a case and literature review. Oral Surg Oral Med Oral Pathol Oral Radiol Endod. 2008;105:155-61.

20. Gadre KS, Waknis P. Intra-oral removal of ectopic third molar in the mandibular condyle. Int J Oral Maxillofac Surg. 2010;39:294-6.

21. Bortoluzzi MC, Manfro R. Treatment for ectopic third molar in the subcondylar region planned with cone beam computed tomography: a case report. J Oral Maxillofac Surg. 2010;68:870-2.

22. Pace C, Holt D, Payne M. An unusual presentation of an ectopic third molar in the condylar region. Aust Dent J. 2010;55:325-7.

23. Procacci P, Albanese M, Sancassani G, Turra M, Morandini B, Bertossi D. Ectopic mandibular third molar: report of two cases by intraoral and extraoral access. Minerva Stomatol. 2011;60:383-90.

24. Shivashankara C, Manjunatha BS, Tanveer A. Ectopic mandibular third molar in subcondylar region: report of a rare case. Oral Maxillofac Surg. 2012;16:153-5.

25. Iglesias-Martin F, Infante-Cossio P, Torres-Carranza E, Prats-Golczer VE, Garcia-Perla-Garcia A. Ectopic third molar in the mandibular condyle: a review of the literature. Med Oral Patol Oral Cir Bucal. 2012;17:e1013-7.

26. Lambade P, Lambade D, Dolas RS, Virani N. Ectopic mandibular third molar leading to osteomyelitis of condyle: a case report with literature review. Oral Maxillofac Surg. 2013;17:127-30.

27. Baykul T, Doğru H, Yasan H, Cina Aksoy M. Clinical impact of ectopic teeth in the maxillary sinus. Auris Nasus Larynx. 2006;33:27781.

28. Verma RK, Bakshi J, Panda NK. Ectopic intranasal tooth: an unusual cause of epistaxis in a child. Ear Nose Throat J. 2012;91:242-4.

29. Srinivasa Prasad T, Sujatha G, Niazi T, Rajesh P. Dentigerous cyst associated with an ectopic third molar in the maxillary sinus: A rare entity. Indian J Dent Res. 2007;18:141-3.

30. Ko SCK, Dover DG, Jordan RCK. Bilateral dentigerous cysts: report of an unusual case and review of the literature. J Can Dent Assoc. 1999;65:49-51 